1 Mokri B, Jack CR, Petty GH. Pseudotumor syndrome associated with cerebral venous sinus occlusion and antiphospholipid antibodies. Stroke 1993; 24: 469-72.

2 Ribes MF. Des recherches faites sur la phlebite. Rev Med $F_{r}$ Etrangere et fournal de clinique de l'hotel Dieu et de la charite de parix 1825; 3: 5-41.

3 Saeki R, Kaneko S, Terasaki S, et al. Mixed types of chronic active hepatitis and primary biliary cirrhosis associated with active hepatitis and primary biliary cirrhosis associated with the anti-phospholipid antibody syndrome:

4 Beales ILP. An acquired pseudo-Bernard Soulier syndrome occurring with autoimmune chronic active hepatitis and anti-cardiolipin antibody. Postgrad Med f 1994; 70: 305-8.
5 Karabudack R, Caner H, Oztekin N, et al. Thrombosis of intracranial venous sinus aetiology clinical findings and prognosis of 56 patients. 7 Neurosurg Sci 1990; 34: 117-21. 6 Stinson J, Tomkin G, McDonald G, et al. Recurrent disseminated intravascular coagulation and fulminant intra disseminated intravascular coagulation and fulminant intra syndrome. Am 7 Hematol 1990; 35: 281-2.

7 Young N, Wong KP. Antibody to cardiolipin causing hepatic infarction in a post partum patient with systemic lupus erythematosus. Aus Radiol 1991; 35: 83-5.

8 Martin PJ, Enevoldson TP. Cerebral venous thrombosis. Postgrad Med f 1996; 72: 72-6.

\title{
Stroke and transient ischaemic attacks in association with substance abuse in a young man
}

\author{
TM Lawson, A Rees
}

\begin{abstract}
Summary
A 22-year-old man with a five-year history of drug and alcohol abuse presented with a left hemiparesis preceded by three transient ischaemic attacks, two of which occurred whilst smoking cannabis. Substance abuse was the only identifiable risk factor for cerebrovascular disease.
\end{abstract}

Keywords: substance abuse, stroke, transient ischaemic attack

Substance abuse has now reached epidemic proportions in the developed world and continues to increase. Both emotional and physical illness are common complications and, in particular, a link between acute stroke and substance abuse has been documented. ${ }^{1,2}$ Although relatively uncommon, substance abuse is now considered to be one of the commonest identifiable factors in the aetiology of acute stroke in young people in the US. Its causal link, however, is insufficiently appreciated in contemporary UK practice. Thus, we wish to emphasise this association by reporting a case of major cerebral infarction preceded by three transient ischaemic events in a 22-yearold Caucasian male whose only risk factor was drug and alcohol abuse.

\section{Case report}

A 22-year-old man was admitted as an emergency with an abrupt onset of a dense left hemiparesis. In the week prior to his admission, he acknowledged that he had heavily abused both cannabis and LSD, but denied taking any amphetamines or ecstasy. However, in the previous five years, he admitted frequent abuse of amphetamines, LSD, ecstasy and cannabis, but denied parenteral drug abuse. $\mathrm{He}$ smoked 20-30 cigarettes a day and consumed approximately 10 units of alcohol per day. There was no significant family history of cerebrovascular disease. Four days prior to his admission, whilst smoking cannabis with friends, he experienced a transient left hemiparesis. This lasted 30 minutes, but resolved completely. Close questioning revealed similar transient left hemiparesis with subjective hemisensory loss two weeks earlier, which lasted 15 minutes and occurred after taking oral amphetamines. Three months earlier, whilst smoking cannabis, he experienced an expressive dysphasia lasting approximately two hours.

Clinical examination revealed him to be normotensive $(140 / 90 \mathrm{mmHg})$ with an established left hemiparesis and sensory inattention. Physical examination was otherwise normal. Investigations included full blood count, urea, creatinine and electrolytes, fasting lipid profile, fasting glucose, $\mathrm{HbAl}$, erythrocyte sedimentation rate, clotting screen, anticardiolipin antibodies, lupus anticoagulant, antithrombin III, $\mathrm{C} 3, \mathrm{C} 4, \mathrm{CH} 50$, protein $\mathrm{C}$ and protein $\mathrm{S}$, VDRL, TPHA, autoimmune screen, electrocardiogram, chest X-ray, carotid Doppler studies and both transthoracic and transoesophageal echocardiography. All these investigations were normal.

Computed tomography of his brain was performed 24 hours after admission. This confirmed an infarct involving the right posterior external capsule, upper part of the internal capsule and corona radiata.

The patient was treated with low dose aspirin and entered a rehabilitation programme. $\mathrm{He}$ is making reasonable progress with intensive physiotherapy, but still has marked residual left-sided weakness.

\section{Discussion}

The first reports of acute stroke secondary to substance abuse were in the 1970 s and were initially received with general scepticism, but the number of reported cases has greatly increased since 1983 with the introduction of the cocaine free-base, 'crack'. ${ }^{3}$ There are 
several reports of stroke (both infarcts and haemorrhages) associated with amphetamines ${ }^{4}$ and heroin, ${ }^{5}$ but the literature is sparse about the possible aetiological role of other commonly abused substances.

This patient gave a clear history of three transient ischaemic attacks (TIAs) prior to his stroke, two of which occurred whilst smoking cannabis. A TIA related to the consumption of cannabis has not, to our knowledge, been previously reported, although a few cases of stroke related to heavy cannabis abuse have been described.$^{6-8}$ One author proposed that alterations in systemic blood pressure may result in vasospasm leading to acute stroke. ${ }^{6}$ A drug-induced reversible vasospasm would be a plausible explanation for the TIAs and this vasospastic theory is also supported by the fact that all cannabis-related cerebrovascular events that have been described have occurred whilst the drug is actually being smoked. This contrasts with strokes linked to other categories of illicit substances where there is often a considerable lag between the timing of the substance abuse and onset of neurological deficit. This has previously been attributed to the questionable veracity of the drug abusers, but it is of interest that it has been noted consistently in several case reports including ours. One explanation would be that an immune-complex vasculitis is of aetiological importance and there is supporting histological evidence for this hypothesis in some cases.9,10

Several other possible mechanisms have been proposed to explain how substance abuse may cause stroke. The aetiology is likely to be multifactorial and vary from case to case. It is difficult to ascertain the possible contribution of any one drug in the pathogenesis of acute stroke as most drug abusers abuse several

1 Caplan LR, Hier DB, Banks G. Current concepts of cerebrovascular disease. Stroke and drug abuse. Strok 1982; 13: $869-872$.

2 Gorelick PB. Stroke from alcohol and drug abuse. A curren social peril: Postgrad Med 1990; 88: $171-8$.

3 Levine SR, Brust JCM, Futtrell N, et al. Cerebrovascular complications of the use of the 'crack' form of alkaloida cocaine. N Engl f Med 1990; 323: 699-704.

4 Citron BP, Halpem M, McCarron M. Necrotizing angiiti associated with drug abuse. N Engl f Med 1970; 283: $1003-$ 11.

5 Brust JC, Richter RW. Stroke associated with addiction to heroin. $\mathcal{f}$ Neurol Neurosurg Psychiatry 1976; 39: 194-9.

\section{Learning/summary points}

- substance abuse is an increasing problem in today's society

- substance abuse is an important risk factor for cerebrovascular disease, especially in young people

- cannabis, in rare cases, may cause stroke or transient ischaemic attacks

- enquiry about substance abuse should be routine when taking a medical history from a patient

substances and often have other risk factors for acute cerebrovascular disease. Alcohol, however, is the most widely abused substance of all and there is now considerable evidence that its abuse is a risk factor for cerebrovascular disease in all age groups. ${ }^{2}$

In the absence of any other risk factors, we feel it is likely that the stroke in this case occurred as a direct result of prolonged abuse of alcohol and illicit substances. We also suggest that the two TIAs resulted from smoking cannabis, but accept that, given its widespread use, this temporal association may be due to chance.

What is evident, however, is that as societal use and dependence on alcohol and illegal substances continues to increase, there will be a concomitant increase in the incidence of acute stroke in young people. We wish to emphasise that substance abuse is an important aetiological risk factor for stroke and transient ischaemic events in the younger age groups. Only increasing awareness and effective education combined with public health measures will help control this growing problem.

6 Zachariah SB. Stroke after heavy marijuana smoking. Stroke 1991; 22: 406-8

7 Beacomfield P, Ginsburg J, Rainburg R. Marijuana smoking: cardiovascular effects in man and possible mechanisms. N Engl f Med 1972; 287: 209-12.

8 Cooles P. Stroke after heavy cannabis smoking (letter). Postgrad Med 1987; 63: 511.

9 Krendel DA, Ditter SM, Frankel MR, Ross WK. Biopsy proven cerebral vasculitis associated with cocaine abuse. Neurology 1990; 40: 1092-4.

10 Lignelli GJ, Bucheit WA. Angiitis in drug abusers. N Engl f Med 1971; 284: 111-3. 